\title{
Tumor necrosis factor- $\alpha$ induces ADAMTS-4 expression in human osteoarthritis chondrocytes
}

\author{
JUAN XUE ${ }^{1}$, JIANLONG WANG $^{2}$, QIANG LIU $^{3}$ and AIJING LUO ${ }^{4,5}$ \\ Departments of ${ }^{1}$ Urology and ${ }^{2}$ Orthopaedics, Third Xiangya Hospital; ${ }^{3}$ Tumor Hospital, Xiangya School of Medicine; \\ ${ }^{4}$ Third Xiangya Hospital; ${ }^{5}$ Key Laboratory of Medical Information Research of Colleges of Hunan Province, \\ Central South University, Changsha, Hunan 410013, P.R. China
}

Received May 23, 2013; Accepted September 25, 2013

DOI: $10.3892 / \mathrm{mmr} .2013 .1729$

\begin{abstract}
Tumor necrosis factor (TNF)- $\alpha$ and a disintegrin and metalloproteinase with thrombospondin motifs 4 (ADAMTS-4) are important in osteoarthritis (OA) cartilage degradation. In the present study, we explored the interaction between the two proteins by examining the effect of TNF- $\alpha$ on ADAMTS-4 expression and activity in osteoarthritic chondrocytes. Human osteoarthritic chondrocytes were treated with TNF- $\alpha$ in different concentrations $(5,15,30,45$ and $60 \mathrm{ng} / \mathrm{ml})$ for different lengths of time (1, 6, 12, 18 and $24 \mathrm{~h}$ ) with or without the TNF receptor 1 (TNFR1) inhibitor SPD304 or different kinase inhibitors. TNF- $\alpha$ increased the ADAMTS- 4 mRNA level in a statistically significant dose- and time-dependent manner within $18 \mathrm{~h}$, which was reflected in the dose-dependent induction of the ADAMTS-4 promoter activity, ADAMTS-4 protein expression and ADAMTS-4 activity. SPD304 $(50 \mu \mathrm{M})$ and p38 mitogen-activated protein kinase (MAPK) siRNA and inhibitor PD169316 $(25 \mu \mathrm{M})$ completely eradicated the promoting effect of TNF- $\alpha$ on ADAMTS- 4 expression and activity. TNF- $\alpha$ induces ADAMTS-4 expression and activity in human osteoarthritic chondrocytes at the transcriptional level via TNFR1 by a p38 MAPK-dependent mechanism. To the best of our knowledge, this is the first evidence of crosstalk between TNF- $\alpha$ and ADAMTS-4 in relation to OA cartilage degradation, which adds novel insight into the pathophysiology of OA and cartilage degradation.
\end{abstract}

\section{Introduction}

Osteoarthritis (OA) is the most common degenerative disease affecting articular cartilage and is characterized by disrupted

Correspondence to: Dr Aijing Luo, Third Xiangya Hospital and Key Laboratory of Medical Information Research of Colleges of Hunan Province, Central South University, 138 Tongzipo Road, Changsha, Hunan 410013, P.R. China

E-mail: luoai3999@126.com

Key words: osteoarthritis, tumor necrosis factor- $\alpha$, chondrocytes, p38 mitogen-activated protein kinase cartilage extracellular matrix homeostasis, ultimately resulting in the loss of cartilage without effective replacement (1-4). $\mathrm{OA}$ is caused in part by the exposure of chondrocytes to inflammatory cytokines, including interleukin-1 $\beta$ (IL-1 $\beta$ ) and tumor necrosis factor (TNF- $\alpha$ ), which stimulate chondrocyte responses that promote catabolism of type II collagen and proteoglycans, thereby compromising cartilage extracellular matrix integrity and tissue homeostasis in OA (2). TNF- $\alpha$ is crucial in cartilage degradation. It promotes the expression of cytokines and chemokines in synovial cells and chondrocytes, thereby maintaining the renewal of local inflammatory mediators (5). The presence of TNF- $\alpha$ correlates with a general loss of cartilage matrix molecules, including type II collagen and aggrecan (5). TNF- $\alpha$ is produced by numerous cell types, including macrophages, lymphocytes, fibroblasts and keratinocytes in response to inflammation, infection and other environmental stresses (6). TNF- $\alpha$ acts by binding to its receptors, TNFR1 (p55) and TNFR2 (p75) on the cell surface. The majority of cells express TNFR1, which is believed to be the major mediator of the cytotoxicity of TNF- $\alpha$ (6). A previous study demonstrated that $\mathrm{p} 55 \mathrm{TNF}-\alpha$ receptor expression is significantly increased in OA chondrocytes ex vivo. Enhanced expression of p55 may contribute to OA cartilage degradation (7).

The pathogenesis of OA is poorly understood, however a major feature is the loss of the two most important components of cartilage extracellular matrix: Type II collagen and aggrecan (8). Aggrecanases represent a class of proteinases belonging to the a disintegrin and metalloproteinase with thrombospondin motifs 4 (ADAMTS) family. Previous studies have demonstrated that ADAMTS 1, 4, 5, 8, 9 and 15 possess aggrecanase activity $(9,10)$. Song et al demonstrated that the knockdown of aggrecanase-1 (ADAMTS-4), aggrecanase-2 (ADAMTS-5) or both attenuates the degradation of aggrecan in human cartilage stimulated by TNF- $\alpha$ and oncostatin M (11). It has been stated that ADAMTS-4 is selectively overexpressed in human OA cartilage and is positively correlated with the degree of cartilage destruction, whereas ADAMTS-5 is similarly expressed in normal and OA cartilages (12). The results suggest that ADAMTS-4 is a major aggrecanase in human OA cartilage and its induction is involved in the pathogenesis of OA.

TNF- $\alpha$ and ADAMTS- 4 are thought to be important in OA cartilage degradation. For the first time, to the best of 
our knowledge, we explored the interaction between the two proteins by examining the effect of TNF- $\alpha$ on ADAMTS-4 expression and activity in human osteoarthritic chondrocytes.

\section{Materials and methods}

Reagents. Recombinant human TNF- $\alpha$, TNFR1 inhibitor SPD304, phosphatidylinositol-3 kinase (PI3K) inhibitor LY294002, protein kinase C inhibitor Go6983, mitogen-activated protein kinase (MAPK) inhibitor PD098059 and p38 MAPK inhibitor PD169316 were purchased from Sigma (St. Louis, MO, USA). TRIzol reagent for RNA isolation and the SYBR Green Master mix were purchased from Invitrogen (Carlsbad, CA, USA) and Applied Biosystems (Foster City, CA, USA), respectively. Anti-ADAMTS-4 (PA1-1749A) antibody was purchased from Thermo Fisher Scientific (Rockford, IL, USA). Anti-phospho-p38 (Thr180/Tyr182; no. 9212) antibody, anti-p38 (no. 8690) antibody and SignalSilence ${ }^{\circledR}$ p38 mitogen-activated protein kinase (MAPK) siRNA (no. 6564) were purchased from Cell Signaling Technology (Danvers, MA, USA). The SensoLyte ${ }^{\circledR} 520$ aggrecanase-1 assay kit (no. 72114) was purchased from AnaSpec Inc. (Fremont, CA, USA). Human ADAMTS-4 promoter-luciferase reporter (with the ADAMTS-4 promoter sequence from 726 nucleotides upstream to 406 nucleotides downstream of the transcription start site inserted upstream of the luciferase cDNA) was generated as previously described (13). A dual-luciferase reporter assay system was purchased from Promega (Madison, WI, USA). Lipofectamine 2000 transfection reagent was purchased from Invitrogen.

Cell culture and treatment. Human osteoarthritic chondrocytes (4020A-05a) and chondrocyte growth medium (411-500) were purchased from Cell Applications Inc. (San Diego, CA, USA). The cells were treated with TNF- $\alpha$ in different concentrations $(5,15,30,45$ and $60 \mathrm{ng} / \mathrm{ml})$ for different lengths of time (1, 6, 12, 18 and $24 \mathrm{~h})$. All kinase inhibitors were dissolved in dimethyl sulfoxide (DMSO; final concentration of DMSO 0.05\%). For kinase inhibitor treatment, chondrocytes were pretreated with the kinase inhibitor for $30 \mathrm{~min}$ and then incubated with the kinase inhibitor and TNF- $\alpha(60 \mathrm{ng} / \mathrm{ml})$ for $18 \mathrm{~h}$. Chondrocytes treated with TNF- $\alpha$ $(60 \mathrm{ng} / \mathrm{ml})+$ DMSO $(0.05 \%)$ were used as a control in the experiments.

Real-time quantitative RT-PCR. RNA were prepared using TRIzol reagent followed by purification with TURBO DNA-free System (Ambion, Austin, TX, USA). The cDNAs were synthesized using SuperScript II reverse transcriptase (Invitrogen). Real-time quantitative PCR was performed on an Abi-Prism 7700 Sequence Detection System using the fluorescent dye SYBR Green Master mix (Applied Biosystems) as described by the manufacturer. The results were normalized against that of the housekeeping gene glyceraldehyde-3-phosphate dehydrogenase $(G A P D H)$ in the same sample. The primers used were as follows: for human ADAMTS-4, 5'-GCAACGTCAAGGCTCCTCTT-3' (forward) and 5'-CTCCACAAATCTACTCAGTGAAGCA-3' (reverse); for human GAPDH, 5'-GACTCATGACCACAGTCCATGC-3' (forward) and 5'-AGAGGCAGGGATGATGTTCTG-3' (reverse). The mRNA level of treated cells was shown as fold changes to that of untreated control cells (designated as 1). Each experiment was repeated three times in triplicates. Results are expressed as the mean $\pm \mathrm{SD}$.

Luciferase reporter assay. Human osteoarthritic chondrocytes were transfected with human ADAMTS-4 promoter-luciferase reporter plasmids using Lipofectamine 2000 transfection reagent (Invitrogen) and then treated with TNF- $\alpha$ (30 or $60 \mathrm{ng} / \mathrm{ml}$ ) for $18 \mathrm{~h}$. Plasmid PRL-CMV encoding Renilla reniformis luciferase (at one-fifth molar ratio to test plasmids) was co-transfected with test plasmids in each transfection as an internal control for data normalization. Luciferase assays were performed with a dual-luciferase reporter assay system (Promega) according to the manufacturer's instructions. Each experiment was repeated three times in duplicates. Untreated human osteoarthritic chondrocytes were used as a control.

ADAMTS-4 activity assay and western blot analysis. ADAMTS-4 activities in cell culture supernatants were determined using a SensoLyte ${ }^{\circledR} 520$ aggrecanase-1 assay kit (AnaSpec Inc.) according to the manufacturer's instructions. In western blot analyses, human osteoarthritic chondrocytes were lysed in $250 \mu \mathrm{l}$ of $2 \mathrm{X}$ SDS loading buffer $(62.5 \mathrm{~mm}$ TrisHCl, pH 6.8, 2\% SDS, 25\% glycerol, $0.01 \%$ bromophenol blue, $5 \%$ 2-mercaptoethanol) and incubated at $95^{\circ} \mathrm{C}$ for $10 \mathrm{~min}$. An equal amount of proteins $(100 \mathrm{~g})$ for each sample were separated by $8-15 \%$ SDS-polyacrylamide gel and blotted onto a polyvinylidene difluoride microporous membrane (Millipore, Billerica, MA, USA). Membranes were incubated for $1 \mathrm{~h}$ with a 1:1,000 dilution of primary antibody and then washed and revealed using secondary antibodies with horseradish peroxidase conjugate $(1: 5,000,1 \mathrm{~h})$. Peroxidase was revealed with an ECL kit (GE Healthcare, Pittsburgh, PA, USA). Proteins were quantified prior to being loaded onto the gel.

Statistical analysis. Statistical analyses were performed with SPSS for Windows 10.0 (IBM, Chicago, IL, USA). Data values were expressed as the means $\pm \mathrm{SD}$. Comparisons of means among multiple groups were performed with one-way ANOVA followed by post hoc pairwise comparisons using Tukey's tests. $\mathrm{P}<0.05$ was considered to indicate a statistically significant difference.

\section{Results}

TNF-a increases ADAMTS- 4 mRNA expression. Cultured human osteoarthritic chondrocytes were treated with TNF- $\alpha$ in different concentrations $(5,15,30,45,60 \mathrm{ng} / \mathrm{ml})$ for different lengths of time (1, 6, 12, 18 and $24 \mathrm{~h})$. ADAMTS-4 mRNA levels were examined using real-time quantitative RT-PCR. The ADAMTS-4 mRNA level of treated cells was shown as fold changes to that of untreated control cells (designated as 1). As displayed in Table I, TNF- $\alpha$ in the concentration range of 5 to $45 \mathrm{ng} / \mathrm{ml}$ increased the ADAMTS- 4 mRNA level in a statistically significant dose- and time-dependent manner within $18 \mathrm{~h}$ of treatment, which was completely eradicated by TNFR1 inhibitor SPD304. By contrast, TNF- $\alpha$ demonstrated no significant effect on ADAMTS-4 expression in normal 
Table I. Relative ADAMTS-4 mRNA levels in human osteoarthritic chondrocytes in the presence of TNF- $\alpha$ with or without TNF receptor inhibitor.

\begin{tabular}{lcclll}
\hline TNF- $\alpha(\mathrm{ng} / \mathrm{ml})$ & $1 \mathrm{~h}$ & \multicolumn{1}{c}{$6 \mathrm{~h}$} & $12 \mathrm{~h}$ & $18 \mathrm{~h}$ & $24 \mathrm{~h}$ \\
\hline 5 & $1.01 \pm 0.04$ & $1.03 \pm 0.03$ & $1.04 \pm 0.05$ & $1.04 \pm 0.05$ & $1.06 \pm 0.07$ \\
15 & $1.04 \pm 0.05$ & $1.27 \pm 0.07^{\mathrm{a}, \mathrm{d}}$ & $1.83 \pm 0.10^{\mathrm{a}, \mathrm{d}, \mathrm{e}}$ & $2.69 \pm 0.17^{\mathrm{a}, \mathrm{d}, \mathrm{e}, \mathrm{f}}$ & $2.82 \pm 0.18^{\mathrm{a}, \mathrm{d}, \mathrm{e}, \mathrm{f}}$ \\
30 & $1.07 \pm 0.05$ & $1.86 \pm 0.12^{\mathrm{a}, \mathrm{b}, \mathrm{d}}$ & $2.71 \pm 0.14^{\mathrm{a}, \mathrm{b}, \mathrm{d}, \mathrm{e}}$ & $3.15 \pm 0.20^{\mathrm{a}, \mathrm{b}, \mathrm{d}, \mathrm{e}, \mathrm{f}}$ & $3.28 \pm 0.19^{\mathrm{a}, \mathrm{b}, \mathrm{d}, \mathrm{e}, \mathrm{f}}$ \\
45 & $1.07 \pm 0.06$ & $2.76 \pm 0.19^{\mathrm{a}, \mathrm{b}, \mathrm{c}, \mathrm{d}}$ & $3.05 \pm 0.13^{\mathrm{a}, \mathrm{b}, \mathrm{c}, \mathrm{d}, \mathrm{e}}$ & $3.66 \pm 0.21^{\mathrm{a}, \mathrm{b}, \mathrm{c}, \mathrm{d}, \mathrm{e}, \mathrm{f}}$ & $3.83 \pm 0.25^{\mathrm{a}, \mathrm{b}, \mathrm{c}, \mathrm{d}, \mathrm{e}, \mathrm{f}}$ \\
60 & $1.08 \pm 0.09$ & $2.88 \pm 0.22^{\mathrm{a}, \mathrm{b}, \mathrm{c}, \mathrm{d}}$ & $3.24 \pm 0.23^{\mathrm{a}, \mathrm{b}, \mathrm{c}, \mathrm{d}, \mathrm{e}}$ & $3.79 \pm 0.26^{\mathrm{a}, \mathrm{b}, \mathrm{c}, \mathrm{d}, \mathrm{e}, \mathrm{f}}$ & $3.92 \pm 0.25^{\mathrm{a}, \mathrm{b}, \mathrm{c}, \mathrm{d}, \mathrm{e}, \mathrm{f}}$ \\
$60+\mathrm{SPD} 304(50 \mu \mathrm{m})$ & $0.94 \pm 0.11$ & $0.99 \pm 0.05$ & $0.97 \pm 0.07$ & $1.03 \pm 0.07$ & $1.05 \pm 0.06$
\end{tabular}

ADAMTS-4 mRNA level of treated human osteoarthritic chondrocytes was shown as fold changes to that of untreated control cells (designated as 1). ${ }^{\mathrm{a}} \mathrm{P}<0.05$ compared with TNF- $\alpha$ treatment at $5 \mathrm{ng} / \mathrm{ml}$ or TNF- $\alpha(60 \mathrm{ng} / \mathrm{ml})+\mathrm{SPD} 304(50 \mu \mathrm{m}) ;{ }^{\mathrm{b}} \mathrm{P}<0.05$ compared with TNF- $\alpha$ treatment at $15 \mathrm{ng} / \mathrm{ml} ;{ }^{~} \mathrm{P}<0.05$ compared with TNF- $\alpha$ treatment at $30 \mathrm{ng} / \mathrm{ml} ;{ }^{\mathrm{d}} \mathrm{P}<0.05$ compared with $1 \mathrm{~h}$ of TNF- $\alpha$ treatment at each concentration; ${ }^{\mathrm{e}} \mathrm{P}<0.05$ compared with 6 h of TNF- $\alpha$ treatment at each concentration and ${ }^{\mathrm{f}} \mathrm{P}<0.05$ compared with $12 \mathrm{~h}$ of TNF- $\alpha$ treatment at each concentration. TNF- $\alpha$, tumor necrosis factor- $\alpha$; ADAMTS-4, a disintegrin and metalloproteinase with thrombospondin motifs 4.

human chondrocytes and its effect on ADAMTS-5 expression was inconsistent in normal and osteoarthritic human chondrocytes (data not shown).

Signaling pathways involved in TNF-a-induced ADAMTS-4 expression and promoter activity. To determine the signaling pathways involved in the promoting effect of TNF- $\alpha$ on ADAMTS-4 expression, we examined the ADAMTS-4 mRNA levels in human osteoarthritic chondrocytes treated with TNF- $\alpha(60 \mathrm{ng} / \mathrm{ml})$ with or without different kinase inhibitors or siRNA for $18 \mathrm{~h}$. As displayed in Table II, inhibition of protein kinase C (Go6983, $250 \mathrm{~nm}$ ), MAPK (PD098059, $25 \mu \mathrm{m}$ ) and PI3K (LY294002, $50 \mu \mathrm{m}$ ) had no significant effect on the ADAMTS-4 mRNA level. By contrast, inhibition of p38 MAPK by the selective inhibitor PD169316 $(25 \mu \mathrm{m})$ or p38 MAPK-specific siRNA completely blocked the promoting effect of TNF- $\alpha$ on ADAMTS-4 expression. Luciferase reporter assays demonstrated that TNF- $\alpha$ dose-dependently increased the ADAMTS-4 promoter activity, which was eliminated by SPD304, PD169316 or p38 MAPK siRNA (Fig. 1). Western blot analyses demonstrated that TNF- $\alpha$ treatment for $18 \mathrm{~h}$ dose-dependently increased ADAMTS-4 expression in human osteoarthritic chondrocytes, which was blocked by SPD304, PD169316 and p38 MAPK siRNA (Fig. 2). A similar data trend was observed with ADAMTS-4 activities in the cell culture media (Fig. 3).

Activation of p38 MAPK in TNF-a-induced ADAMTS-4 expression. Phosphorylation and activation of p38 MAPK is involved in TNF- $\alpha$-induced biological effects $(14,15)$. As displayed in Fig. 4, western blot analyses demonstrated that TNF- $\alpha$ treatment for $18 \mathrm{~h}$ dose-dependently increased phosphorylated p38 MAPK (Thr180/Tyr182) levels in human osteoarthritic chondrocytes, which was blocked by SPD304, PD169316 or p38 (MAPK) siRNA. Fig. 4 also demonstrates that the p38 siRNA knocked down $>70 \%$ of endogenous p38 MAPK expression. Taken together, the results indicate that TNF- $\alpha$ induces ADAMTS-4 expression and activity in human osteoarthritic chondrocytes at the transcriptional level via TNFR1 by a p38 MAPK-dependent mechanism.
Table II. Relative ADAMTS-4 mRNA levels in human osteoarthritic chondrocytes in the presence of TNF- $\alpha$ with or without kinase inhibitors or siRNA.

Treatment

Relative ADAMTS-4 mRNA level

\begin{tabular}{ll}
\hline Control & $3.77 \pm 0.24^{\mathrm{a}}$ \\
+PD169316 $(25 \mu \mathrm{m})$ & $1.05 \pm 0.09$ \\
+Go6983 $(250 \mathrm{~nm})$ & $3.68 \pm 0.21^{\mathrm{a}}$ \\
+PD098059 $(25 \mu \mathrm{m})$ & $3.72 \pm 0.26^{\mathrm{a}}$ \\
+LY294002 $(50 \mu \mathrm{m})$ & $3.65 \pm 0.29^{\mathrm{a}}$ \\
+p38 MAPK siRNA & $0.97 \pm 0.15$ \\
\hline
\end{tabular}

Human osteoarthritic chondrocytes were pretreated with the kinase inhibitor for $30 \mathrm{~min}$ and then incubated with the kinase inhibitor and TNF- $\alpha(60 \mathrm{ng} / \mathrm{ml})$ for $18 \mathrm{~h}$. All kinase inhibitors were dissolved in DMSO (final concentration of DMSO $0.05 \%$ ). Human osteoarthritic chondrocytes treated with TNF- $\alpha(60 \mathrm{ng} / \mathrm{ml})+$ DMSO $(0.05 \%)$ was used as the control. The ADAMTS-4 mRNA level of treated cells was shown as fold changes to that of control cells treated with $0.05 \%$ DMSO (designated as 1 ). ${ }^{a} \mathrm{P}<0.05$ compared with TNF- $\alpha$ $(60 \mathrm{ng} / \mathrm{ml})+\mathrm{PD} 169316(25 \mu \mathrm{m})$ or TNF- $\alpha(60 \mathrm{ng} / \mathrm{ml})+\mathrm{p} 38$ MAPK siRNA. MAPK, mitogen-activated protein kinase; TNF- $\alpha$, tumor necrosis factor $\alpha$; DMSO, dimethyl sulfoxide; ADAMTS-4, a disintegrin and metalloproteinase with thrombospondin motifs 4 .

\section{Discussion}

Cartilage degradation in OA constitutes a major structural change in the joint, which may severely impair its function and cause pain and disability (16). Among the inflammatory mediators associated with OA, TNF- $\alpha$ is an established key mediator for cartilage (5). ADAMTS-4 is believed to be important in the degradation of aggrecan during the progression of joint diseases (17). In the present study, we provided, to the best of our knowledge, the first evidence for a regulatory effect of TNF- $\alpha$ on ADAMTS-4 expression and activity in human osteoarthritic chondrocytes. 


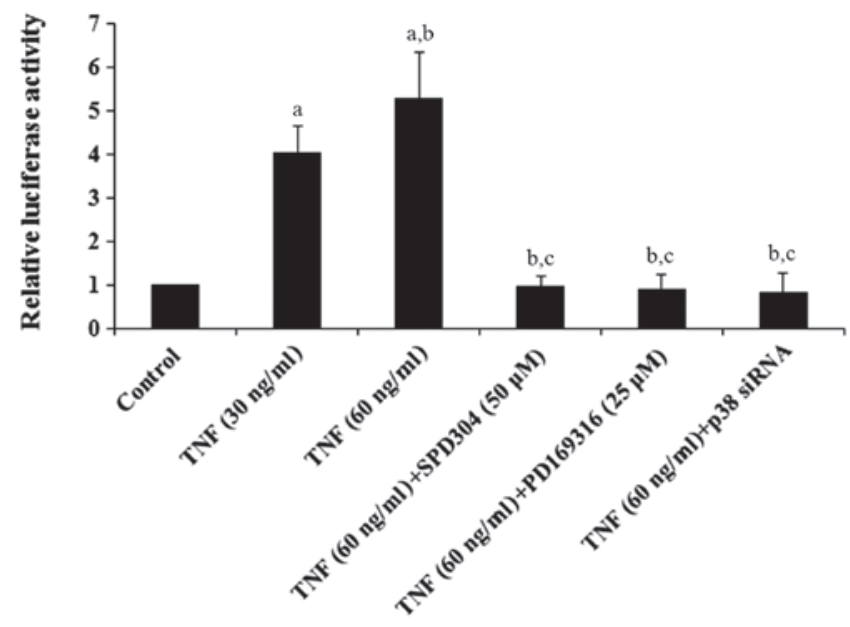

Figure 1. Effect of TNF- $\alpha$ on ADAMTS-4 promoter activities in human osteoarthritic chondrocytes. Human osteoarthritic chondrocytes were transfected with human ADAMTS-4 promoter-luciferase reporter plasmids and then treated with TNF- $\alpha$ ( 30 or $60 \mathrm{ng} / \mathrm{ml})$ for $18 \mathrm{~h}$. Normalized luciferase activity was expressed as fold changes to that of untreated control cells (designated as 1 ). ${ }^{\mathrm{a}} \mathrm{P}<0.05$ compared with untreated control cells; ${ }^{\mathrm{b}} \mathrm{P}<0.05$ compared with TNF- $\alpha$ treatment at $30 \mathrm{ng} / \mathrm{ml} ;{ }^{\circ} \mathrm{P}<0.05$ compared with TNF- $\alpha$ treatment at $60 \mathrm{ng} / \mathrm{ml}$. TNF- $\alpha$, tumor necrosis factor- $\alpha$; ADAMTS-4, a disintegrin and metalloproteinase with thrombospondin motifs 4 .
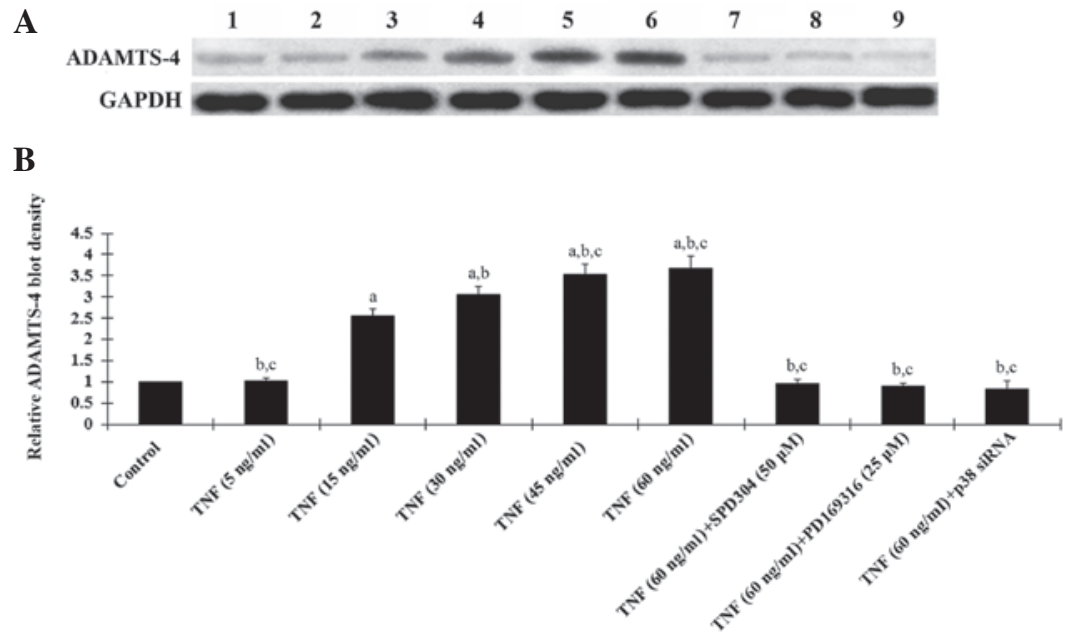

Figure 2. Western blot analysis of ADAMTS-4 expression in human osteoarthritic chondrocytes. (A) Human osteoarthritic chondrocytes were treated with TNF- $\alpha(5,15,30,45$ and $60 \mathrm{ng} / \mathrm{ml})$ with or without SPD304 $(50 \mu \mathrm{m})$, PD169316 $(25 \mu \mathrm{m})$ or p38 (MAPK) siRNA for $18 \mathrm{~h}$. Cell lysates were subject to western blot analyses for ADAMTS-4 expression. Lane 1, lysates from untreated human osteoarthritic chondrocytes were used as a control; lane 2, TNF- $\alpha$ (5 ng/ml); lane 3, TNF- $\alpha(15 \mathrm{ng} / \mathrm{ml})$; lane 4, TNF- $\alpha$ (30 ng/ml); lane 5, TNF- $\alpha(45 \mathrm{ng} / \mathrm{ml})$; lane 6, TNF- $\alpha(60 \mathrm{ng} / \mathrm{ml}) ;$ lane 7, TNF- $\alpha(60 \mathrm{ng} / \mathrm{ml})+$ SPD304 (50 $\mu \mathrm{m}) ; 1$ lane 8 , TNF- $\alpha(60 \mathrm{ng} / \mathrm{ml})+$ PD169316 $(25 \mu \mathrm{m})$; lane 9, TNF- $\alpha(60 \mathrm{ng} / \mathrm{ml})+$ p38 (MAPK) siRNA. GAPDH blotting was used as a loading control. (B) ADAMTS-4 and GAPDH blots were measured by densitometry. The density of the ADAMTS-4 blot was normalized against that of GAPDH to obtain a relative density, which was expressed as fold changes to that of untreated control cells (designated as 1 ). ${ }^{\mathrm{P}} \mathrm{P}<0.05$ compared with untreated control cells; ${ }^{\mathrm{b}} \mathrm{P}<0.05$ compared with TNF- $\alpha$ treatment at $15 \mathrm{ng} / \mathrm{ml} ;{ }^{~} \mathrm{P}<0.05$ compared with TNF- $\alpha$ treatment at $30 \mathrm{ng} / \mathrm{ml}$. TNF- $\alpha$, tumor necrosis factor $\alpha$; ADAMTS-4, a disintegrin and metalloproteinase with thrombospondin motifs 4; SPD304, TNFR1 inhibitor; PD169316, p38 MAPK inhibitor; MAPK, mitogen activated protein kinase; GAPDH, glyceraldehyde-3-phosphate dehydrogenase.

TNF- $\alpha$ is produced in a variety of cell types, including macrophages, lymphocytes, fibroblasts and keratinocytes in response to inflammation, infection and other environmental stresses (6). TNF- $\alpha$ in the concentration range of 1-100 ng/ml has been used in chondrocytes in vitro (18). In the present study, we used $5-60 \mathrm{ng} / \mathrm{ml}$ of TNF- $\alpha$ to determine whether TNF- $\alpha$ is able to regulate ADAMTS-4 expression in osteoarthritic chondrocytes. Within this testing concentration range, while TNF- $\alpha$ at $5 \mathrm{ng} / \mathrm{ml}$ had no significant effect on ADAMTS-4 expression, a statistically significant dose-dependent effect of TNF- $\alpha$ on ADAMTS- 4 expression was observed in the concentration range of 5-45 $\mathrm{ng} / \mathrm{ml}$ and the effect reached a plateau in the range of $45-60 \mathrm{ng} / \mathrm{ml}$. TNF- $\alpha$ at a concentration as low as $15 \mathrm{ng} / \mathrm{ml}$ increased ADAMTS- 4 expression by $>2.5$ fold within $18 \mathrm{~h}$, suggesting that TNF- $\alpha$ is a strong positive regulator of ADAMTS- 4 expression.

The depletion of aggrecan in articular cartilage is an early event in the pathogenesis of OA. ADAMTS-4 and ADAMTS-5 are believed to be important in the degradation of aggrecan (17). Recent studies suggest that ADAMTS-4 may be the principal aggrecanase of aggrecan degradation in human OA as it is selectively overexpressed in human OA cartilage and is positively correlated with the degree of cartilage destruction, whereas ADAMTS-5 is similarly expressed 


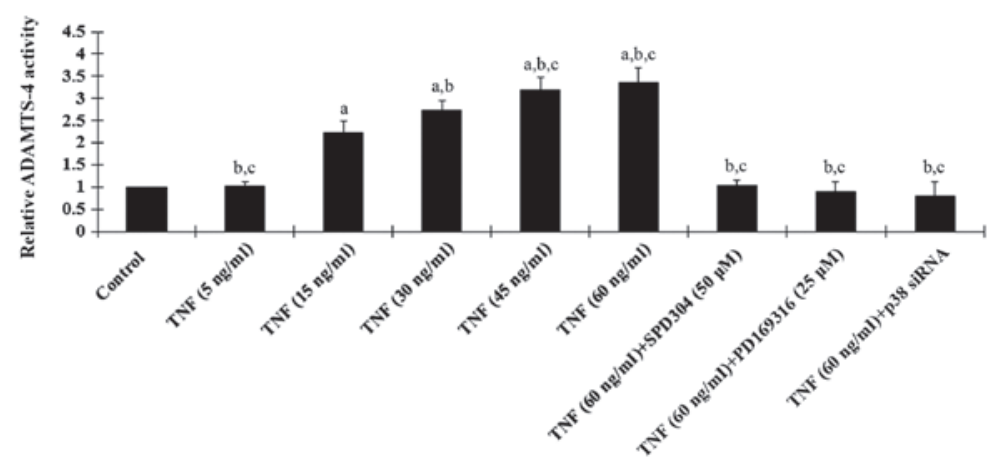

Figure 3. ADAMTS- 4 activity in human osteoarthritic chondrocytes. Human osteoarthritic chondrocytes were treated with TNF- $\alpha(5,15,30,45 \mathrm{and} 60 \mathrm{ng} / \mathrm{ml})$ with or without SPD304 $(50 \mu \mathrm{m})$, PD169316 $(25 \mu \mathrm{m})$ or p38 (MAPK) siRNA for $18 \mathrm{~h}$. ADAMTS-4 activities were measured and expressed as fold changes to that of untreated control cells (designated as 1 ). ${ }^{a} \mathrm{P}<0.05$ compared with untreated control cells; ${ }^{b} \mathrm{P}<0.05$ compared with $\mathrm{TNF}-\alpha$ treatment at $15 \mathrm{ng} / \mathrm{ml}$; ${ }^{\mathrm{c}} \mathrm{P}<0.05$ compared with TNF- $\alpha$ treatment at $30 \mathrm{ng} / \mathrm{ml}$. TNF- $\alpha$, tumor necrosis factor- $\alpha$; ADAMTS- 4 , a disintegrin and metalloproteinase with thrombospondin motifs 4; SPD304, TNFR1 inhibitor; PD169316, p38 MAPK inhibitor; MAPK, mitogen activated protein kinase.

A

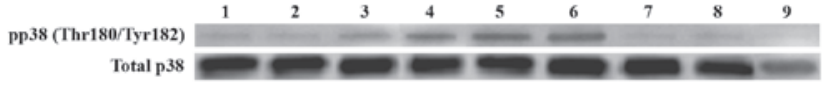

B

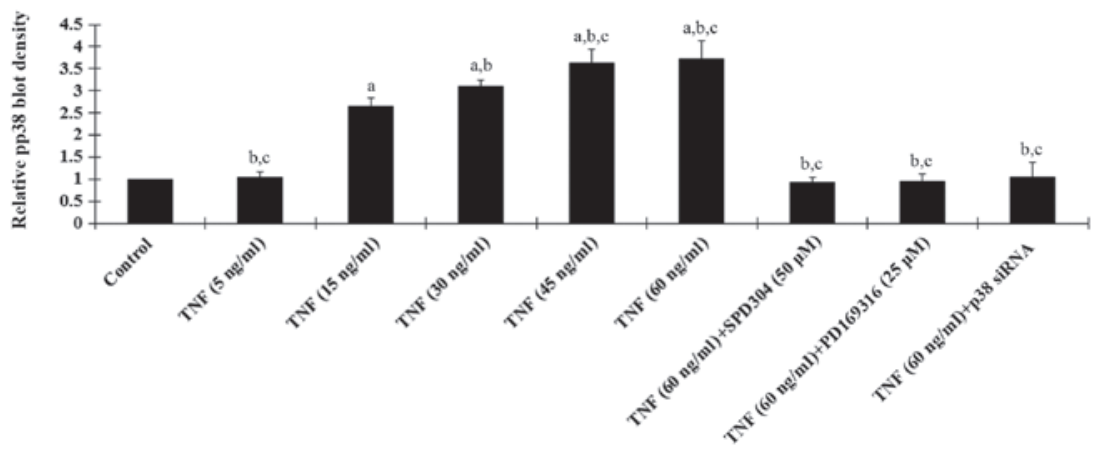

Figure 4. Western blot analysis of phosphorylated p38 MAPK levels in human osteoarthritic chondrocytes. (A) The levels of phosphorylated p38 MAPK (pp38) and total p38 MAPK in human osteoarthritic chondrocytes treated with TNF- $\alpha(5,15,30,45$ and $60 \mathrm{ng} / \mathrm{ml}$ ) with or without SPD304 (50 $\mu \mathrm{m})$, PD169316 $(25 \mu \mathrm{m})$ or p38 (MAPK) siRNA for $18 \mathrm{~h}$ were analyzed with western blot analysis. Lane 1, lysates from untreated human osteoarthritic chondrocytes were used as a control; lane 2, TNF- $\alpha(5 \mathrm{ng} / \mathrm{ml})$; lane 3, TNF- $\alpha(15 \mathrm{ng} / \mathrm{ml}) ;$ lane 4 , TNF- $\alpha(30 \mathrm{ng} / \mathrm{ml}) ;$ lane 5 , TNF- $\alpha$ (45 ng/ml); lane 6, TNF- $\alpha$ (60 ng/ml); lane 7, TNF- $\alpha$ $(60 \mathrm{ng} / \mathrm{ml})+$ SPD304 $(50 \mu \mathrm{m})$; lane 8, TNF- $\alpha(60 \mathrm{ng} / \mathrm{ml})+$ PD169316 $(25 \mu \mathrm{m})$; lane 9, TNF- $\alpha(60 \mathrm{ng} / \mathrm{ml})+$ p38 (MAPK) siRNA. (B) pp38 (Thr180/Tyr182) and total p38 MAPK levels were measured by densitometry. The density of pp38 blot was normalized against that of total p38 MAPK levels to obtain a relative density, which was expressed as fold changes to that of untreated control cells (designated as 1 ). ${ }^{a} \mathrm{P}<0.05$ compared with untreated control cells; ${ }^{b} \mathrm{P}<0.05$ compared with TNF- $\alpha$ treatment at $15 \mathrm{ng} / \mathrm{ml}$; ${ }^{~} \mathrm{P}<0.05$ compared with TNF- $\alpha$ treatment at $30 \mathrm{ng} / \mathrm{ml}$. TNF- $\alpha$, tumor necrosis factor- $\alpha$; SPD304, TNFR1 inhibitor; PD169316, p38 MAPK inhibitor; MAPK, mitogen activated protein kinase.

in normal and OA cartilages $(12,19)$. Indeed, we demonstrated that TNF- $\alpha$ had no induction effect on ADAMTS-4 expression in normal human chondrocytes. In addition, the effect of TNF- $\alpha$ on ADAMTS-5 expression was inconsistent in normal and osteoarthritic human chondrocytes. Thus, we only selected ADAMTS-4 as the target of the present study.

The main extracellular matrix macromolecules of the articular cartilage are type II collagen and aggrecan and the pathogenesis of OA involves the degradation of aggrecan and type II collagen $(20,21)$. The presence of TNF- $\alpha$ reportedly correlates with the loss of type II collagen and aggrecan in OA cartilage due to increased production of matrix metalloproteinases (5). Aggrecan has a protective effect against collagen degradation. Mechanistically, type II collagen is exposed due to the degradation of aggrecan and the exposed collagen becomes an easy target for enzymatic degradation by collagenase $(20,21)$. Since our findings demonstrate that
ADAMTS-4 is a downstream target of TNF- $\alpha$ signaling in human osteoarthritic chondrocytes, the loss of aggrecan and type II collagen caused by TNF- $\alpha$ in OA cartilage is at least partially mediated by ADAMTS-4, besides matrix metalloproteinases. Further studies are needed to explore this issue in vivo. Our results demonstrated that TNF- $\alpha$ enhanced the ADAMTS-4 promoter activity and increased the ADAMTS-4 mRNA level, suggesting that TNF- $\alpha$ induced ADAMTS-4 expression at the transcriptional level. The underlying transcriptional regulatory mechanisms aim to be elaborated in our future studies.

In conclusion, we demonstrated that TNF- $\alpha$ induces ADAMTS-4 expression and activity in human osteoarthritic chondrocytes at the transcriptional level via TNFR1 by a p38 MAPK-dependent mechanism. To the best of our knowledge, this is the first evidence of crosstalk between TNF- $\alpha$ and ADAMTS-4 in relation to OA cartilage degradation, which 
adds novel insight into the pathophysiology of OA and cartilage degradation.

\section{References}

1. Iannone F and Lapadula G: The pathophysiology of osteoarthritis. Aging Clin Exp Res 15: 364-372, 2003.

2. Goldring MB and Goldring SR: Osteoarthritis. J Cell Physiol 213: 626-634, 2007.

3. Davidson RK, Waters JG, Kevorkian L, et al: Expression profiling of metalloproteinases and their inhibitors in synovium and cartilage. Arthritis Res Ther 8: R124, 2006.

4. Burrage PS, Mix KS and Brinckerhoff CE: Matrix metalloproteinases: role in arthritis. Front Biosci 11: 529-543, 2006.

5. Lee SW, Song YS, Lee SY, et al: Downregulation of protein kinase CK2 activity facilitates tumor necrosis factor- $\alpha$-mediated chondrocyte death through apoptosis and autophagy. PLoS One 6: e19163, 2011.

6. Englaro W, Bahadoran P, Bertolotto C, et al: Tumor necrosis factor alpha-mediated inhibition of melanogenesis is dependent on nuclear factor kappa B activation. Oncogene 18: 1553-1559, 1999.

7. Westacott CI, Atkins RM, Dieppe PA and Elson CJ: Tumor necrosis factor-alpha receptor expression on chondrocytes isolated from human articular cartilage. J Rheumatol 21: $1710-1715,1994$

8. Wieland HA, Michaelis M, Kirschbaum BJ and Rudolphi KA: Osteoarthritis - an untreatable disease? Nat Rev Drug Discov 4: 331-344, 2005

9. Porter S, Clark IM, Kevorkian L and Edwards DR: The ADAMTS metalloproteinases. Biochem J 386: 15-27, 2005.

10. Sandy JD: A contentious issue finds some clarity: on the independent and complementary roles of aggrecanase activity and MMP activity in human joint aggrecanolysis. Osteoarthritis Cartilage 14: 95-100, 2006.

11. Song RH, Tortorella MD, Malfait AM, et al: Aggrecan degradation in human articular cartilage explants is mediated by both ADAMTS-4 and ADAMTS-5. Arthritis Rheum 56: 575-585, 2007.
12. Naito S, Shiomi T, Okada A, et al: Expression of ADAMTS4 (aggrecanase-1) in human osteoarthritic cartilage. Pathol Int 57: 703-711, 2007.

13. Salter RC, Arnaoutakis K, Michael DR, et al: The expression of a disintegrin and metalloproteinase with thrombospondin motifs 4 in human macrophages is inhibited by the anti-atherogenic cytokine transforming growth factor- $\beta$ and requires Smads, p38 mitogen-activated protein kinase and c-Jun. Int J Biochem Cell Biol 43: 805-811, 2011.

14. Li YP, Chen Y, John J, et al: TNF-alpha acts via p38 MAPK to stimulate expression of the ubiquitin ligase atrogin1/MAFbx in skeletal muscle. FASEB J 19: 362-370, 2005.

15. Chen SE, Jin B and Li YP: TNF-alpha regulates myogenesis and muscle regeneration by activating p38 MAPK. Am J Physiol Cell Physiol 292: C1660-C1671, 2007.

16. Manacu CA, Martel-Pelletier J, Roy-Beaudry M, et al: Endothelin-1 in osteoarthritic chondrocytes triggers nitric oxide production and upregulates collagenase production. Arthritis Res Ther 7: R324-R332, 2005.

17. He Y, Zheng Q, Simonsen O, et al: The development and characterization of a competitive ELISA for measuring active ADAMTS-4 in a bovine cartilage ex vivo model. Matrix Biol 32: 143-151, 2013

18. Kim AH and Song WY: TNF-alpha-mediated apoptosis in chondrocytes sensitized by MG132 or actinomycin D. Biochem Biophys Res Commun 295: 937-944, 2002.

19. Zhang E, Yan X, Zhang M, et al: Aggrecanases in the human synovial fluid at different stages of osteoarthritis. Clin Rheumatol 32: 797-803, 2013.

20. Eyre D: Collagen of articular cartilage. Arthritis Res 4: 30-35, 2002.

21. Roughley PJ: Articular cartilage and changes in arthritis: noncollagenous proteins and proteoglycans in the extracellular matrix of cartilage. Arthritis Res 3: 342-347, 2001. 